\title{
Histopathological Analysis of Nephrectomy Specimens: Experience from A Tertiary Care Hospital
}

\author{
Authors \\ Dr Suma M T ${ }^{1}$, Dr Usha Poothiode ${ }^{2}$ \\ ${ }^{1}$ Associate Professor, Department of Pathology, Government Medical College, Thrissur Kerala, India \\ Mobile no: 9847678928, Email: suma1879@ gmail.com \\ ${ }^{2}$ Professor of Pathology, MOSC Medical College, Kolenchery
}

\begin{abstract}
Introduction: Renal Cell carcinoma is a malignancy of renal tubular epithelium and constitute 3\% of all adult malignancies and constitute 80-90\% of renal tumors. The morphological features including the histopathologic type, nuclear grade and extent of tumor involvement determine the aggressiveness and prognosis of Renal Cell Carcinoma.

Methods: 83 cases who underwent radicalor simple nephrectomy in a tertiary health care centerover a span of 4 years were included in the study. Their gross and microscopic features were studied.

Results: Renal cell carcinoma shows varying morphologic features in gross and histologic appearance. The predominant histologic variant is Clear cell variant and predominant nuclear grade of tumors is grade II.

Conclusion: Thorough evaluation of morphological parameters in Renal Cell Carcinoma is very essential for planning therapy and predicting the disease outcome.

Keywords: Kidney, Renal cell carcinoma, Clear cell carcinoma.
\end{abstract}

\section{INTRODUCTION}

Nephrectomy is a common surgical procedure done for neoplastic and non-neoplastic lesions of kidney. First successful nephrectomy was performed by German surgeon Gustav Simon in 1869. There are various neoplastic and non-neoplastic indications for this procedure such as renal cell carcinoma, non functioning kidneys and congenital cystic lesions. Renal cell carcinoma in adults and wilms tumor in children predominates among malignancies which needs radical nephrectomy ${ }^{1}$. Nephrectomy for renal cell carcinoma is rapidly being modified to allow partial nephrectomy. Hydronephrosis, pyelonephritis, cystic lesions and non functioning kidneys are the common indications for simple nephrectomy.
About 2,10,000 new cases of renal cell carcinomas are detected every year and more than 10,000 deaths are due to renal cell carcinoma annually. Globally there is $25 \%$ increase in incidence of renal cell carcinoma including almost all regions and ethnic groups. $^{2}$ Cigarette smoking, hypertension and obesity are the most important risk factors of renal cell carcinoma. Other risk factors are Tuberoussclerosis, epithelioid angiomyolipoma, von HippelLindau disease and other familial syndromes, renal transplantation, dialysis and acquired renal cystic disease.

Renal cell carcinoma is a disease of adults with average age of 55-60 years at diagnosis. About two third cases of renal cell carcinoma are localised at 
presentation. $40 \%$ of patients develops metastases and die from the disease even with complete excision. Numerous prognostic factors have identified including tumor stage, grade, histological type, renal sinus involvement and extra-renal spread. Histopathological parameters have gained acceptance for assessing prognosis in routine clinical practice, especially the Fuhrman nuclear grading. Most urothelial (transitional cell) carcinomas of the renal pelvis occur in adults (in whom they constitute about $7 \%$ of all primary renal carcinomas), but pediatric cases also have been documented ${ }^{3}$

In this study analysis of various neoplastic and non neoplastic diseases of kidney was done. Histopathological sub typing of renal cell carcinoma is very important in prognosis because each subtype is associated with distinct genetic abnormalities and clinical behavior. Morphological subtyping of RCC was done and prognostic factors like stage, grade, extra capsular extension, involvement of perinephric fat and invasion of renal vein was studied.

\section{OBJECTIVES}

1. To study the spectrum of diseases in nephrectomy specimens

2. Morphological subtyping of renal malignancies and to analyze different tumor related prognostic factors in Renal cell carcinom

\section{MATERIALS AND METHODS}

The present study was conducted in a tertiary care center in South India for a period of 4 years. Study group included both adults and children who underwent radical nephrectomies for a clinical diagnosis of renal malignancies or for non neoplastic lesions of kidneys. Clinical data were collected by proforma given to the patient, chart review and from surgical records. Pathology reports and materials were reviewed and data including histopathological diagnosis, size, pathological stage and grade of tumor were recorded.

Specimens were fixed in $10 \%$ formal in for about 18-24 hours and examined grossly for abnormalities including hydronephrotic changes, inflamatory changes, stones and PUJ obstructions. In case of malignancies size of tumor, invasion of perirenal fat, capsule, ureter, renal vessels, adrenal were noted. Sampling was done from tumor, capsules, renal pelvis, adjacent parenchyma, ureter, renal vessels and lymph nodes. Tissue was processed and $\mathrm{H} \& \mathrm{E}$ staining was done.

A specific diagnosis was given to non neoplasticspecimens like pyelonephritis, hydronephrosis, nephrolithiasis, congenital malformations including cystic diseases of kidney. Renal malignancies were sub classified morphologically according to WHO classification. The grading done by Fuhrman system and staging according to TNM system. Extracapsular extension, involvement of perinephric fat, renal vein and adrenal were noted. In case of Wilms tumour it was reported as tumors with favorable histology or tumors with unfavorable histology. Study was done after getting ethical approval from institutional ethical committee. No statistical analysis was required.

\section{OBSERVATIONS}

A total of 83 nephrectomies received, 51 nephrectomies done for malignancies including pediatric neoplasms and 32 nephrectomies done for non-neoplastic lesions of kidney.

Table 1. Type of nephrectomy specimens

\begin{tabular}{|l|c|c|}
\hline Type of lesion & Number & Percentage \\
\hline Neoplastic & 51 & 61 \\
\hline Non neoplastic & 32 & 39 \\
\hline Total & 83 & 100 \\
\hline
\end{tabular}

$57 \%$ of renal malignancies were Renal cell carcinoma and $21 \%$ Transitional cell carcinoma. Pediatric neoplasms constitute $16 \%$. There was two cases of Angiomyolipoma and one case of multilocular cyst.

Table 2 Types ofRenal tumors.

\begin{tabular}{|l|c|c|}
\hline Type of lesion & No & percentage\% \\
\hline Rcc & 29 & 57 \\
\hline Tcc & 11 & 21 \\
\hline Wilms & 6 & 12 \\
\hline Css & 2 & 4 \\
\hline Aml & 2 & 4 \\
\hline
\end{tabular}




\begin{tabular}{|l|c|c|} 
Multilocular cyst & 1 & 2 \\
\hline Total & 51 & 100 \\
\hline
\end{tabular}

Of the 51 cases of malignancies $71 \%$ of patients were male and $29 \%$ were female with male: female ratio of 2.4:1. Renal cell carcinoma is generally a disease of adult and $31 \%$ cases was seen in between 61-70 years. Four cases were in the younger age group (20-40). 69\% cases of renal cell carcinoma were on the right side and $31 \%$ were on the left side and all the cases of RCC were unilateral.

\section{Presentation of renal tumors}

Patients presented with costovertebral pain (45\%) hematuria (27\%) and mass (15\%). $13 \%$ of patients showed other mode of presentations. The classic triad of mass, hematuria and flank pain were seen only in $6 \%$ of patients. Most of the TCC patients presented with flank pain. One of the patients came with bone pain due to bone metastasis from TCC of renal pelvis. Two cases of angiomyolipoma were included in this study. One of the patient came with complaints of infertility. Renal mass was an incidental finding in this patient. This patient had tuberous sclerosis with adenoma sebaceum, subungualfibromas and bilateral angiomyolipomas.

Table 3: Presentation of renal tumours

\begin{tabular}{|l|c|c|}
\hline Presentation & Number & Percentage \% \\
\hline Flank pain & 24 & 48 \\
\hline Hematuria & 14 & 27 \\
\hline Mass & 8 & 15 \\
\hline Fever & 2 & 4 \\
\hline Bone pain & 1 & 2 \\
\hline Infertility & 1 & 2 \\
\hline UTI & 1 & 2 \\
\hline
\end{tabular}

\section{Morphological profile of Renal cell carcinoma}

$31 \%$ of RCC observed in 61-70 years (male 66\%, female $34 \%$ ). Four cases were in the younger age group (20-40years). Renal cell carcinoma has got predilection to develop on the right side of the kidney. In the present study 20 cases of RCC were on the right side $(69 \%)$ and 9 were on the left side $(31 \%)$. The commonest location of tumor was in the upper pole of kidney (78\%) Grossly more than $80 \%$ of RCC showed the classical variegated appearance composed of yellowish tumor with hemorrhage and necrosis. Rest of them presented as large tumors with extensive necrotic areas. Sarcomatoid RCC showed grey white solid areas.

The most common variant of Renal cell carcinoma was the conventional clear cell type constituting about 69 percent. Clear cell RCC were of high nuclear grade and high stage compared to other morphological variants of Renal cell carcinoma.

Table 4: Histologic variants of rcc

\begin{tabular}{|l|c|c|}
\hline VARIANT & N0 & $\%$ \\
\hline Clearcell & 20 & 70 \\
\hline Papillary & 3 & 10 \\
\hline Rcc-Sarcomatoid & 2 & 7 \\
\hline Unclassified & 2 & 7 \\
\hline Chromophobe & 1 & 3 \\
\hline Multicystic RCC & 1 & 3 \\
\hline Total & 29 & 100 \\
\hline
\end{tabular}

\section{RCC at younger age group}

3 of our patients were young adults between $24-37$ years they presented with large tumors with average size $19 \mathrm{cms}$. Histologically two were of clear cell Type and one was papillary RCC, all of them showed higher nuclear grades 3or 4. Two cases showed extensive sarcomatoid areas along with clear cell areas. Predominant age group affected was 61-70 years and stage2 disease was common.

Table 5: Distribution of patients by Tumor stage

\begin{tabular}{|l|c|c|c|c|c|}
\hline Age & $\begin{array}{c}\text { Stage } \\
1\end{array}$ & $\begin{array}{c}\text { Stage } \\
2\end{array}$ & $\begin{array}{c}\text { Stage } \\
3\end{array}$ & Total & $\%$ \\
\hline $21-30$ & & 1 & & 1 & 3 \\
\hline $31-40$ & 1 & 2 & & 3 & 10 \\
\hline $41-50$ & 3 & 4 & 1 & 8 & 28 \\
\hline $51-60$ & 1 & 3 & 2 & 6 & 21 \\
\hline $61-70$ & 3 & 4 & 3 & 10 & 35 \\
\hline $71-80$ & & & 1 & 1 & 3 \\
\hline Total & 8 & 14 & 7 & 29 & 100 \\
\hline
\end{tabular}

$40 \%$ of RCC was stage T1 (40\%) among this $63 \%$ belonged to $\mathrm{T} 1 \mathrm{a}$ stage and $37 \%$ to $\mathrm{T} 1 \mathrm{~b}$ stage.

Table 6: T1 tumors 


\begin{tabular}{|l|l|l|l|}
\hline AGE & $\begin{array}{l}\text { NUCLEAR } \\
\text { GRADE }\end{array}$ & $\begin{array}{l}\text { SIZE in } \\
\mathrm{cm}\end{array}$ & HISTOLOGY \\
\hline 50 & 1 & $6 \mathrm{X} 4$ & RCC \\
\hline 67 & 2 & $5 \times 4$ & RCC \\
\hline 50 & 3 & $5 \times 3.5$ & RCC \\
\hline 61 & 2 & $4 \times 4$ & RCC \\
\hline 53 & 2 & $3.5 \times 3.5$ & RCC \\
\hline 35 & 3 & $3.5 \times 2.5$ & RCC \\
\hline 50 & 2 & $2.5 \times 2.5$ & RCC \\
\hline 65 & 3 & $1 \mathrm{X} 1$ & RCC \\
\hline
\end{tabular}

\section{T2 Tumors}

Most of the tumors were T2 stage and nuclear grade2. Irrespective of the stage of RCC, majority of tumors were of nuclear grade 2 constituting about $55 \%$.

Table 7: T2 Tumors

\begin{tabular}{|l|c|c|c|}
\hline AGE & $\begin{array}{c}\text { NUCLEAR } \\
\text { GRADE }\end{array}$ & $\begin{array}{c}\text { SIZE in } \\
\mathrm{cm}\end{array}$ & HISTOLOGY \\
\hline 68 & 1 & $8 \times 5.5$ & RCC \\
\hline 37 & 1 & $17 \times 12$ & RCC \\
\hline 46 & 2 & $10.5 \times 7.5$ & RCC \\
\hline 42 & 2 & $8 \times 7$ & RCC \\
\hline 52 & 2 & $12 \times 5$ & RCC \\
\hline 48 & 2 & $10 \times 6$ & RCC \\
\hline 70 & 2 & $8 \times 5$ & RCC \\
\hline 59 & 2 & $7 \times 5$ & RCC \\
\hline 62 & 2 & $7 \times 6 \times 5$ & RCC \\
\hline 40 & 2 & $8 \times 4$ & RCC \\
\hline 65 & 3 & $9.5 \times 6.5$ & RCC \\
\hline 60 & 3 & $8 \times 5$ & RCC \\
\hline 41 & 3 & $9.5 \times 7.5$ & RCC \\
\hline 24 & 4 & $20 \times 17$ & RCC \\
\hline
\end{tabular}

Out of 29 cases of RCC 7were stage 3 tumors including four cases ofT $3 a$, one case ofT $3 b$, T3a $\mathrm{N} 1$ and $\mathrm{T} 3 \mathrm{~b} \mathrm{~N} 2$ one case each.

Table 8: T3 Tumours

\begin{tabular}{|l|c|c|c|}
\hline AGE & $\begin{array}{c}\text { NUCLEAR } \\
\text { GRADE }\end{array}$ & $\begin{array}{c}\text { SIZE in } \\
\mathrm{cm}\end{array}$ & HISTOLOGY \\
\hline 6 & 2 & $8.5 \mathrm{X} 4$ & RCC \\
\hline 60 & 2 & $8 \times 6$ & RCC \\
\hline 61 & 2 & $7.5 \mathrm{X} 6.5$ & RCC \\
\hline 72 & 2 & $4 \mathrm{X} 4$ & RCC \\
\hline 65 & 2 & $10 \mathrm{X} 5$ & RCC \\
\hline 66 & 3 & 5.5 & RCC \\
\hline 49 & 3 & $9 \times 7$ & RCC \\
\hline
\end{tabular}

$53 \%$ of Rcc were of grade 2.
FUHRMAN NUCLEAR GRADE IN RCC

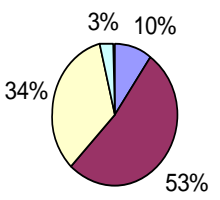

$\square$ GRADE 1

$\square$ GRADE2

$\square$ GRADE3

$\square$ GRADE4

\section{Pediatric neoplasm}

We received 8 pediatric neoplasms, 6 cases of wilms tumor and two cases of clear cell sarcoma. All these cases were treated by radical nephrectomy. Morphologically wilms tumor showed triphasic pattern and favorable histology.

Table 9 : Paediatric renal tumours

\begin{tabular}{|l|l|l|l|l|}
\hline Histology & Age & Sex & Presentation & size \\
\hline Wilms & 1 & M & Haematuria & $8 \times 6 \times 4$ \\
\hline Wilms & 1.5 & M & Mass & $12 \times 7$ \\
\hline Wilms & 1.5 & F & Mass & $9 \times 8.5 \times 3$ \\
\hline Css & 2 & M & Mass & $8 \times 6$ \\
\hline Wilms & 2.5 & M & Mass & $12 \times 9$ \\
\hline Wilms & 3 & M & Mass & $10 \times 7 \times 4$ \\
\hline Wilms & 4.5 & M & abd pain & $11 \times 8$ \\
\hline Css & 2.5 & F & mass & $7 \times 6$ \\
\hline
\end{tabular}

\section{Transitional cell carcinoma}

Transitional cell carcinoma constitute about 21 percent of all renal malignancies. All the cases were of higher grade at presentation and most of the patients presented with flank pain. One of the patient came with bone pain. Histopathological examination showed TCC of renal pelvis with bone metastasis. Two of the patients were having duplex kidney with double ureters, of which one patient had synchronous malignancy of urinary bladder. Urine sediments were examined for all patients with clinically suspected or CT diagnosed malignancy of kidney and renal pelvis. Out of eleven patients with a histological diagnose of TCC of renal pelvis six patients $(55 \%)$ showed positive urine cytology before surgery. One case of TCC showed unusual morphology with sarcomatoid areas, mucinous areas and extensive necrosis in a 71 year old male patient.

Table 10 : Transitional cell carcinoma

\begin{tabular}{|l|c|c|c|c|}
\hline SL & AGE & PRESENTATION & SIZE & GRADE \\
NO & SEX & & & \\
\hline
\end{tabular}




\section{JMSCR Vol||05||Issue||09||Page 27687-27694||September}

\begin{tabular}{|l|c|c|c|c|}
\hline 1 & $78 \mathrm{M}$ & Flankpain & $12 \times 9 \times 7$ & High \\
\hline 2 & $71 \mathrm{M}$ & Flankpain & $22 \times 18 \times 10$ & High \\
\hline 3 & $46 \mathrm{M}$ & Bonepain & $3 \times 2 \times 1$ & High \\
\hline 4 & $64 \mathrm{M}$ & Flankpain & $16 \times 10 \times 8$ & High \\
\hline 5 & $56 \mathrm{~F}$ & Haematuria & $9 \times 6 \times 6$ & High \\
\hline 6 & $57 \mathrm{M}$ & Flankpain & $10 \times 5 \times 2$ & High \\
\hline 7 & $58 \mathrm{M}$ & Haematuria & $12 \mathrm{z} 10 \times 6$ & High \\
\hline 8 & $65 \mathrm{M}$ & Mass & $8 \times 4 \times 3$ & High \\
\hline 9 & $57 \mathrm{M}$ & Flankpain & $13 \times 10 \times 3$ & High \\
\hline 10 & $65 \mathrm{~F}$ & Flankpain & $4 \times 5 \times 4$ & High \\
\hline 11 & $59 \mathrm{M}$ & Flankpain & $8 \times 7 \times 5$ & High \\
\hline
\end{tabular}

\section{Non neoplastic lesions of kidney}

We received 32 nephrectomy specimen which were removed for loss of function constituting about $39 \%$ of all total nephrectomies. All were simple nephrectomy specimens. Mainly they were removed for pyelonephritis, hydronephrosis, nephrolithiasis, congenital anomalies like Renal dysplasia and pelviureteric junction obstruction

Table 11: Non neoplastic lesions of kidney

\begin{tabular}{|l|c|c|}
\hline Lesion & No of cases & Percentage \\
\hline Hydronephrosis & 10 & 31 \\
\hline Pyelonephritis & 11 & 31 \\
\hline Dysplastic kidney & 5 & 16 \\
\hline Duplex kidney & 3 & 7 \\
\hline Lithiasis & 2 & 3 \\
\hline Stricture & 1 & 3 \\
\hline
\end{tabular}

Figure 1: Macroscopy of renaltumors

Figure 1 A renal cell carcinoma

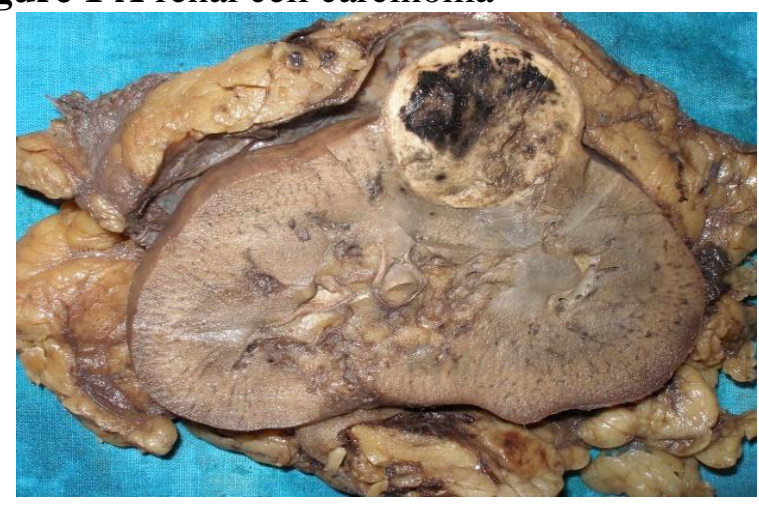

Figure 1 B Multi cystic nephroma

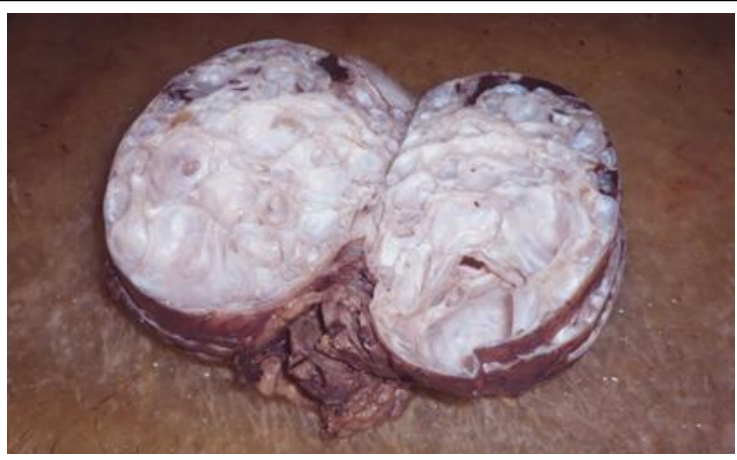

Figure 1C Xanthogranulomatous pyelonephritis

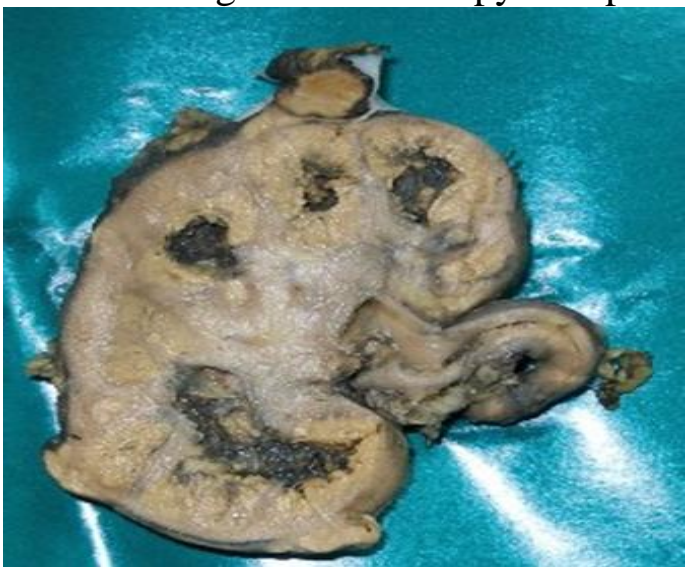

Figure 1 D Angiomyolipoma

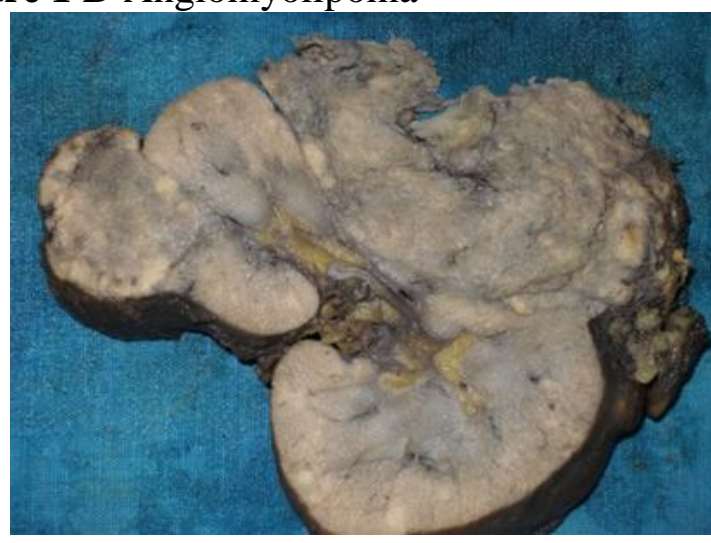

Figure 1 E Nephroblastoma

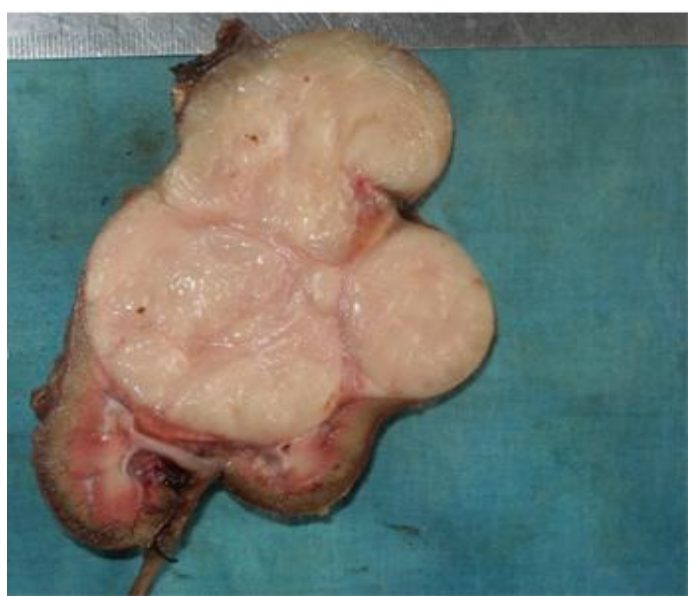

Figure 2 : Microscopic appearance of renal tumors 
Figure 2A Clear cell carcinoma

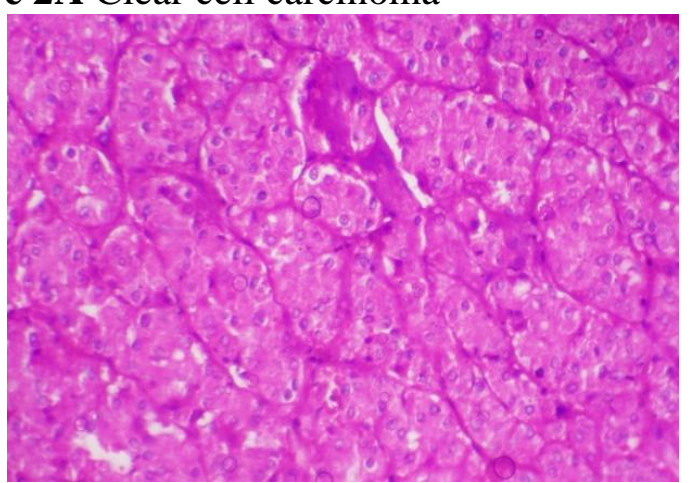

Figure 2 B Papillary renal cell carcinoma

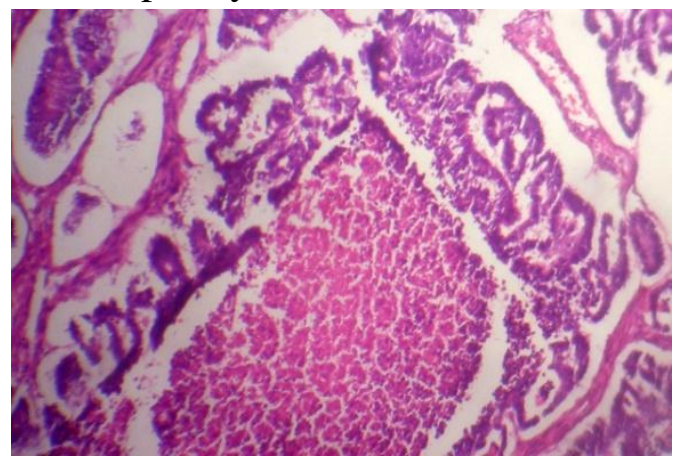

Figure 2 C Xanthogranulomatous pyelonephritis

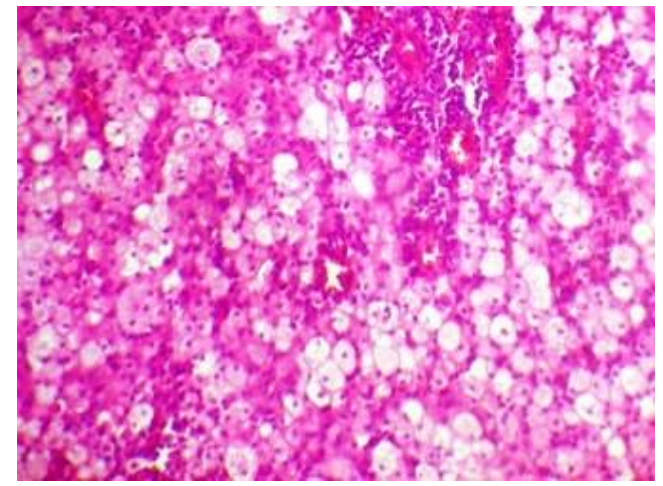

Figure 2 E Nephroblastoma

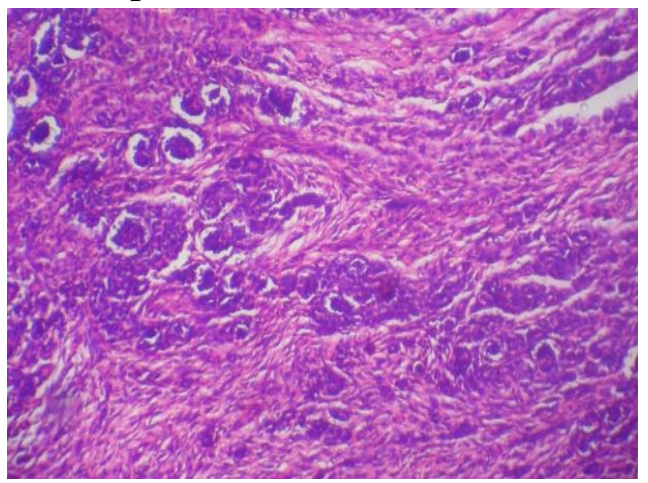

DISCUSSION
83 nephrectomies were included in this study out of this 51 cases were renal malignancies and 32 were non neoplastic lesions. Renal cell carcinoma was the commenest malignancy, constituting about $57 \%$ similar to the observation made by Storkel et $\mathrm{al}^{4}$. Males were affected more than females [males : females - 2.3:1] This pattern is similar to observations made by [Chang TS, Chang SK etal 1980] $]^{5}$. The increased RCC incidence may be linked to certain risk factors like smoking, hypertension, obesity, occupational factors and genetic factors. Age of patients ranged from 20 to 70 years with peak incidence in fifth to seventh decade. The commonest presentation of renal cell carcinoma were flank pain (46\%) haematuria (28\%) abdominal mass $(16 \%)$ repeated urinary tract infection $(2 \%)$ and non specific symptoms like fever and body ache in $(4 \%)$. The classical triad of symptom was seen only in $6 \%$ of the patients similar to observations by Hiroaki Masuda et al, ${ }^{6}$ and they also found out that if a patient presents with above mentioned classical triad of symptoms the overall prognosis was poor. All the cases of TCC were of higher grade malignancies and 55\% showed positive urine cytology for malignant cells. Study results of Raica $\mathrm{M}$, Mederle $\mathrm{O}$ et $\mathrm{al}^{7}$ suggested the urine cytology as a simple screening test for the early detection of urinary tract malignancy. Out of 11 patients with transitional cell carcinoma 9 patients underwent radical nephrectomy and 2 patients nephroureterectomy with bladder cuff resection. Two patients with TCC showed duplex kidney in the same side of malignancy. One case of Transitional cell carcinoma presented with bone pain due to metastasis and bone marrow biopsy showed osteoblastic metastasis from transitional cell carcinoma which is a rare occurrence. In our study 2 cases of Angiomyolipoma were included of which one case was that of a young lady who presented with infertility and features of Tuberous sclerosis. A total of 8 cases of pediatric neoplasms were received, 6 cases of Wilms tumor and 2cases of clear cell sarcoma. In patients with Wilms tumor, radical nephrectomies were performed and 
combined radiation and/or chemotherapy after surgery were given for cure of tumor.

Grossly more than $80 \%$ of RCC showed the classical variegated appearance. Rest of which included very large tumours with extensive necrotic areas, sarcomatoid RCC with grey white solid areas and tumors with cystic change. Histological subtyping is important in prognosis of renal cell carcinoma. According to various studies there are significant differences in outcome for the different histologic subtypes of RCC, highlighting the need for accurate subtyping (Mahul B. Amin, M.D.; Mitual B. $)^{8}$ and among the morphological subtypes classical clear cell variant has got the worst prognosis. In our study also clear cell RCCs were of larger size and higher stage at presentation compared to other morphological variants of Renal cell carcinoma like papillary and chromophobe RCC. This observations are similar to studies conducted by (B. A. Birnbaumet al) ${ }^{9}$

Smoking habit was found in 70 percent of the male patients. A significant association was noted between smoking and renal cell carcinoma and Transitional cell carcinoma. 94 percent patients were normotensive and only 6 percent were hypertensive at the time of surgery. 3 of our patients were young adults between 24 -37 years, they presented with large tumors of average size $19 \mathrm{cms}$. Histologically these tumors showed nuclear grade 3 and 4 and clear cell and papillary morphology. Studies conducted by Renshaw AA, Fletcher JA ${ }^{10}$ that the clinicopathologic features of renal cell carcinomas in children and young adults differ from those arising in older adults and these tumors are characteristically high-grade, papillary tumors with numerous calcifications. Leuschner I, Harms D and Schmidt $\mathrm{D}^{11}$ et al found that young patients presenting with large masses shows high grade RCCs with poor prognosis. RCC with sarcomatoid areas showed extensive spindle cell areas along with clear cell areas.Both cases were observed in female patients in the fourth decade contributing about $6 \%$ of total Renal cell carcinomas.

$40 \%$ of RCC was stage T1 $(40 \%)$ among this T1a tumors showed high nuclear grade and papillary architecture. T1b tumors was predominantly of nuclear grade2.Same observation was mace by Bretheu Lechivallier E et al. ${ }^{12}$ Study conducted by Gauraguptha et al shows that symptomatic $\mathrm{T} 1 \mathrm{~b}$ RCC had higher nuclear grade and papillary architecture. Studies conducted by Raymond M. Hsuet al found out that there is no significant difference in stage and nuclear grade in tumors of 3 $\mathrm{cm}$ size and tumors between $3-7 \mathrm{~cm}$. Most of the tumors in our study was T2 stage and irrespective of the stage of RCC majority of tumors were of nuclear grade 2 constituting about 55\%.Out of 29 cases of RCC 7were stage T3 tumors. The distribution of tumors were T3a 4 cases, T3b 1case,T3a N1and T 3b N2 one case each

Transitional cell carcinoma constitute about 21 percent of all renal malignancies. All the cases were of high grade tumors and common presentation wasflank pain similar to studies conducted by Nielsen $\mathrm{k} \&$ Ostri $\mathrm{P}$ et $\mathrm{al}^{13}$. Two of the patients had duplex kidney with double ureters of which one patient had synchronous malignancy of urinary bladder. Urine sediments were examined for all patients with clinically suspected or CT diagnosed malignancy ofkidney and renal pelvis. Out of eleven patients with a histological diagnose of TCC of renal pelvis six patients $(55 \%)$ showed positive urine cytology. One case of high grade TCC showed unusualmorphology with sarcomatoid areas mucinous areas and extensive necrosis in a 71 year old male patient. Perez Montiel D et al states that unusual morphology are usually of high grade.

Most common pediatric neoplasm was nephroblastoma and Clear cell sarcoma. Most of the neoplasms were observed below three years. Main pathological changes observed in non neoplasticlesions include pyelonephritis, hydron-ephrosis followed by congenital anomalies like dysplastic kidneys and duplex kidneys.Among the cystic lesions cystic dysplastic kidney predominated with abortive glomeruli,primitive ducts surrounded by condensed mesenchyme and immature cartilage. ${ }^{14}$ Two cases of angiomyolipoma were included in this study. One of the patient came with complaints of infertility. Renal mass was an incidental finding in 
this patient. This patient had tuberous sclerosis with adenoma sebaceum, subungualfibromas and bilateral angiomyolipomas. EI Malik EM et al also described one case of angiomyolipoma with tuberous sclerosis. ${ }^{15}$

\section{CONCLUSION}

Renal cell carcinoma constituted 57percent of total renal malignancies. The age group of Renal cell carcinoma was 61-70 years with a male to female ratio of 2.3:1. Clear cell RCC was the predominant histological subtype of RCC. Majority of Renal cell carcinoma were stage II and Grade II.

\section{REFERENCES}

1. Ozen H, Colowick A, Freiha FS, Incidently discovered solid renal masses:What are they ? Br J Urol.1993;72:274-6.

2. Cohen HT, Mc Govern FJ: Renal-cell carcinoma. N Engl J Med2005;353:2477-2490

3. Guinan P, Vogelzang NJ, Randazzo R, Sene r S, Chmiel J, Fremgen A, Sylvester J: Renal pelvic cancer. A review of 611 patients treated in Illinois 1975-1985. Cancer Incidence and End Results Committee. Urology 1992; 40:393-399

4. Störkel S Rumpelt HJ Histopathology and classification of renal cell tumors (adenomas, oncocytomas and carcinomas). The basic cytological and histopathological elements and their use for diagnostics.Pathol Res Pract.1986 May;181(2):125-43.

5. Chang TS, Chang SK. 1980.PatientPlus articles, renal tumours, Egton Medical Information Systems DocID: 2722 Document Version: 22 DocRef: p 686.

6. Hiroaki Masuda et al, Can symptoms predict the prognosis of RCC a multivariate analysis of 320 patients.

7. Raica M Mederle $\mathrm{O}$ et al Urinary cytology in diagnosis of epithelial tumours of urotheliumDiagnCytopathol 1993,9;197-201

8. Mahul B. Amin, M.D.; Mitual B.) Prognostic impact of adult renal epithelial neoplasms an experience of 405 cases. Am J SurgPathol 2002,26;281-291.

9. B. A. Birnbaum et al:Renal cell carcinoma acorrelation of 100 tumours with ct findings - journal abdominal imaging volume 19may 1999 pages 262-266.

10. Renshaw AA, Granter SR, Fletcher JA: Renal cell carcinoma in hildren and young adults increased incidence of papillary architecture and unique subtypes Am J surg path 1999; 23;795-802.

11. Leuschner I, Harms D and Schmidt D1991 Renal Cell Carcinoma in children: Histology, immunohistochemistry, and follow up 10 cases. Med PediatrOncol19 : 33-41.

12. Bretheu Lechivallier E et al.Prognostic value of nuclear grade of renal cell carcinoma. Bretheau D, Lechevallier E, de Fromont M, Sault MC, Rampal M, Coulange C. Department of Urology, Salvator Hospital, Marseille, France.

13. Nielsen k Ostri P 1988 Primary tumours of the renal pelvis : evaluation of clinical and pathological features in consecutive series of 10 years. J Urol 140: 19-21

14. Maizals M, Simpson SB. Primitive ducts of renal dysplasia induced by culturing ureteric buds denuded of condensed renal blastema. Science. 1983;219: 509 - 510

15. EI Malik EM, Mmon SR,Ibrahim AL, AI Gizawi. Nephrectomy in adults:Asir Hospital Experience. Saudi J Kidney Dis Transpl 1997;8:423-7. 